\title{
Classical Forms of Congenital Adrenal Hyperplasia due to 21-Hydroxylase Deficiency in Adults
}

\author{
Anne Bachelot Zeina Chakthoura Agnès Rouxel Jérome Dulon \\ Philippe Touraine
}

Department of Endocrinology and Reproductive Medicine, Groupe Hospitalier Pitié-Salpétrière, and Centre de Référence des Maladies Endocriniennes Rares de la Croissance, Paris, France

\section{Key Words \\ Congenital adrenal hyperplasia $\cdot$ Fertility $\cdot$ Bone mineral density $\cdot$ Body mass index $\cdot$ Adrenal rest tumors $\cdot 21-\mathrm{OH}$ deficiency}

carefully follow up these patients, from childhood through to adulthood, to avoid these complications and to ensure treatment compliance and tight control of the adrenal androgens.

Copyright $\odot 2008$ S. Karger AG, Basel

\begin{abstract}
During childhood, the main aims of the medical treatment of congenital adrenal hyperplasia (CAH) secondary to 21-hydroxylase are to prevent salt loss and virilization and to attain normal stature and normal puberty. As such, there is a narrow therapeutic window through which the intended results can be achieved. In adulthood, the clinical management has received little attention, but recent studies have shown the relevance of long-term follow-up of these patients. The aims here are to review the multiple clinical, hormonal and metabolic abnormalities that could be found in adult CAH patients as such a decrease in bone mineral density, overweight and disturbed reproductive functions. In women with classic $\mathrm{CAH}$, a low fertility rate is reported, and is probably the consequence of multiple factors including neuroendocrine and hormonal factors, feminizing surgery, and psychological factors. Men with $\mathrm{CAH}$ may present hypogonadism either through the effect of adrenal rests or from suppression of gonadotropins resulting in infertility. Therefore a multidisciplinary team with knowledge of $\mathrm{CAH}$ should
\end{abstract}

\section{KARGER}

Fax +4161306 1234

E-Mail karger@karger.ch

www.karger.com (c) 2008 S. Karger AG, Basel

0301-0163/08/0694-0203\$24.50/0

Accessible online at:

www.karger.com/hre

\section{Introduction}

Congenital adrenal hyperplasia (CAH, MIM 201910) describes a group of inherited autosomal recessive disorders characterized by enzyme defects in the steroidogenic pathways that lead to the biosynthesis of cortisol, aldosterone and androgens. The relative decrease in cortisol production, acting via the classic negative feedback loop, results in the increased secretion of ACTH from the pituitary gland and to subsequent hyperplasia of the adrenals (fig. 1A, B) [1]. Deficiency of the 21-hydroxylase (21$\mathrm{OH}$ ) enzyme is the most common form of $\mathrm{CAH}$, accounting for more than $95 \%$ of cases and is one of the most commonly known autosomal recessive disorders. $21-\mathrm{OH}$ is a cytochrome $\mathrm{P} 450$ that catalyses the conversion of 17-hydroxyprogesterone (17-OHP) to 11-deoxycortisol (fig. 1C). Cortisol deficiency results in the ACTH-induced accumulation of substrate precursors such as 17$\mathrm{OHP}$ and progesterone, and to increased secretion of ad- 
A

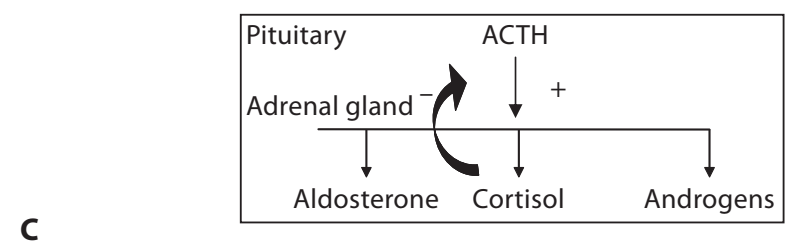

B

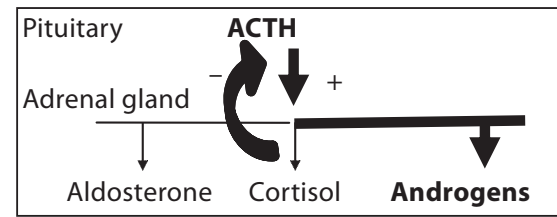

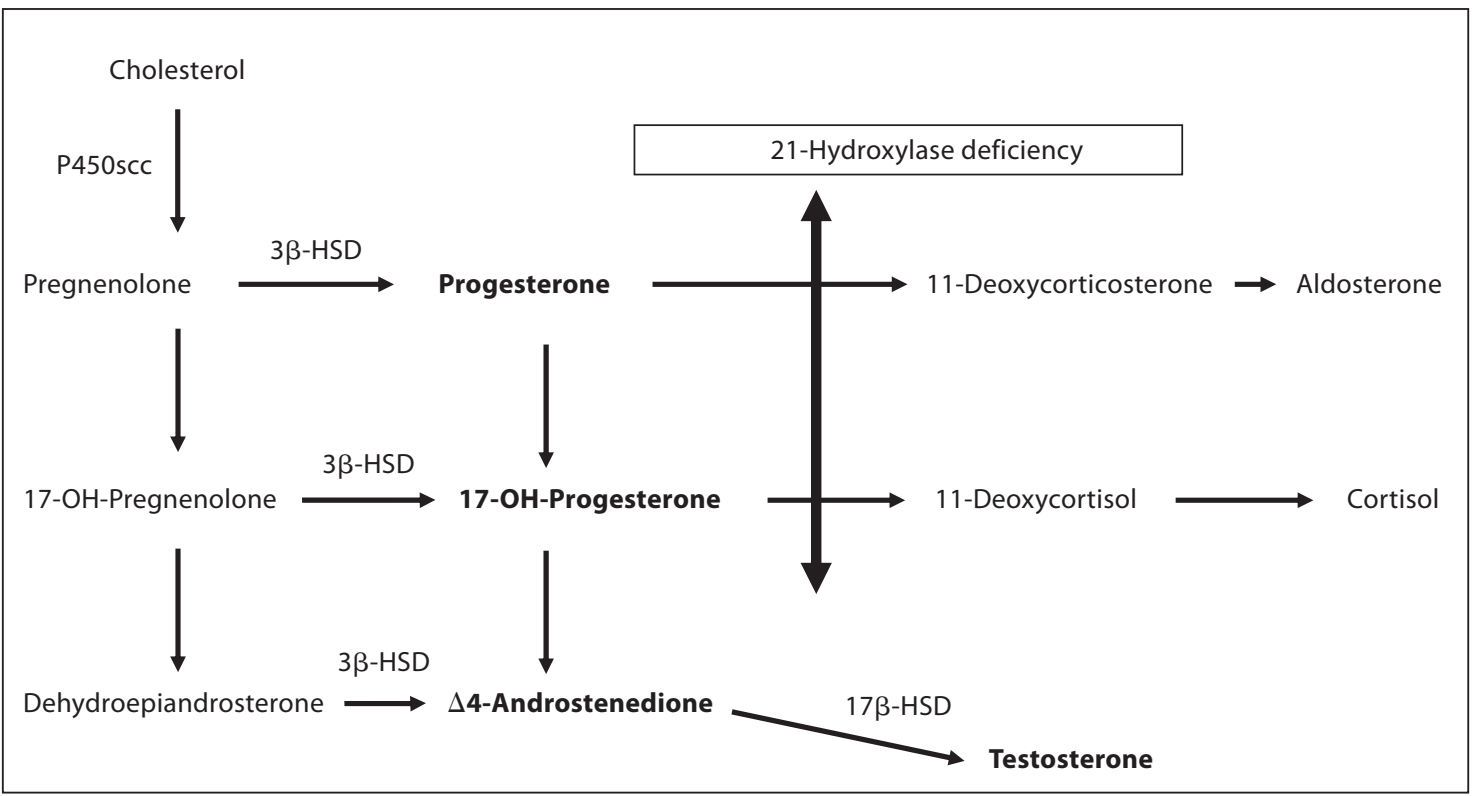

Fig. 1. Steroidogenesis in patients with $\mathrm{CAH}$ due to 21-OH deficiency. Adrenal steroid regulation in physiology (A) and in $\mathrm{CAH}$ due to 21-OH deficiency (B). Disruption of the adrenal steroidogenesis in case of 21-OH deficiency $(\mathbf{C})$.

renal androgens, especially androstenedione [1]. The same enzyme is also required for mineralocorticoid production, the deficiency of which leads to impaired synthesis of aldosterone [1]. CAH due to $21-\mathrm{OH}$ deficiency is the result of deletions or deleterious mutations of the active gene CYP21. Duplicated 21-OH genes, an active gene CYP21 and a pseudogene (CYP21P) are located on chromosome $6 \mathrm{p}$, within the major human histocompatibility complex, about $30 \mathrm{~kb}$ apart, adjacent to and alternating with the $\mathrm{C} 4 \mathrm{~B}$ and $\mathrm{C} 4 \mathrm{~A}$ genes encoding for the fourth component of serum complement $[2,3]$. Many different mutations of the CYP21 gene have been identified causing varying degrees of impairment of $21-\mathrm{OH}$ activity that result in a spectrum of disease expression [4]. Most patients are compound heterozygotes, and the clinical phenotype is generally related to the less severely mutated allele and, consequently, to the residual 21-OH activity.

Indeed, $\mathrm{CAH}$ is classified according to symptoms and signs and to age at presentation. The clinical phenotype is typically classified as classic, the severe form, or nonclassic (NCF), the mild or late-onset form. Classic CAH is subclassified as salt-wasting (SW) or simple-virilizing (SV) forms, reflecting the degree of aldosterone deficiency. Several studies have suggested high concordance rates between genotype and phenotype in patients with the classic form of CAH, but less observed in NCF patients. Classical disease occurs in approximately $1 / 15,000$ births, while the NCF occurs in approximately $1 \%$ of the general population, many of them being undiagnosed [5]. The lives of patients with $\mathrm{CAH}$ have improved greatly since the discovery that cortisone was an effective treatment for the disorder in the 1950s. Neonatal screening is being done in several countries, and DNA-based prenatal diagnosis is now feasible [6]. Current treatment is intended to reduce excessive ACTH and the consequent increase in androgen production by substituting for deficient cortisol synthesis and, when necessary, mineralocorticoid substitution. During childhood, the main aims of the 
Table 1. Summary of indications and complications of adrenalectomy in adult CAH patients

\begin{tabular}{llllll}
\hline Reference & Patients & $\begin{array}{l}\text { Age } \\
\text { years }\end{array}$ & SW/SV & Indication & Postoperative complications \\
\hline Warinner et al. [11] & 3 & $14,19,30$ & $2 / 1$ & Poor hormonal control & Adrenal crisis in 1 patient \\
Bruining et al. [12] & 1 & 31 & $1 / 0$ & Irregular menses, virilization, obesity & None reported \\
Gmyrek et al. [13] & 2 & 22,28 & $2 / 0$ & Amenorrhea, hirsutism, acne & None reported \\
Ogilvie et al. [14] & 5 & $15,21,34,34,37$ & $4 / 0$ & Fertility, obesity, virilization & Adrenal crisis in 2 patients \\
\hline
\end{tabular}

medical treatment of $\mathrm{CAH}$ secondary to $21-\mathrm{OH}$ are to prevent salt loss and virilization, to achieve normal stature and to undergo normal puberty [5]. Undertreatment exposes the patient to the risk of adrenal crisis and allows increased adrenal androgen production, with consequent advancement of bone age and loss of growth potential. Overtreatment, however, results in growth retardation, truncal obesity and osteopenia through the effects of steroids on growth hormone secretion and bone metabolism. In adulthood, the aims of the medical treatment are to substitute cortisol and, when necessary, aldosterone deficiency, to ensure normal fertility and to avoid the long-term consequences of glucocorticoid use. In such an intervention, there is a narrow therapeutic window through which the intended results can be achieved.

\section{Steroid Substitution}

\section{Glucocorticoid Treatment}

Substitution therapy with glucocorticoids is offered in an attempt to correct adrenal deficiency and thus to suppress the excessive secretion of $\mathrm{CRH}$ and ACTH by the hypothalamus and anterior pituitary, respectively, and to reduce the circulating concentrations of adrenal androgens and androgen precursors. The preferred glucocorticoid option is hydrocortisone, because its short half-life minimizes growth suppression as well as other adverse side effects of more potent, longer-acting glucocorticoids. One study suggested that in patients with classic $21-\mathrm{OH}$ deficiency, hydrocortisone replacement therapy should be administered during the period of increased hypothalamic-pituitary-adrenal activity, i.e. between 4 a.m. and 4 p.m. [7]. The highest hydrocortisone dose should be given in the morning because circulating cortisol concentrations obtained after evening doses are likely to be undetectable by the time of the rapid rise in 17-OHP concentrations at 4 a.m. Blood investigations performed as part of monitoring of $\mathrm{CAH}$ patients should include an-

Long-Term Follow-Up of CAH Patients drostenedione, testosterone and 17-OHP concentrations obtained in the morning before the oral dose of hydrocortisone is given [7]. Indeed, serum androstenedione concentrations obtained early in the morning and before the administration of oral hydrocortisone correlate strongly with integrated 17-OHP concentrations and can be used as a reliable marker of the adequacy of adrenocortical suppression if a single blood sample is to be obtained [8]. However, it is important to note that there is actually no consensus on treating adults, concerning the type of glucocorticoids, the use of a reverse circadian pattern of glucocorticoid treatment, or the use of a dose based on weight or surface area. In a recent study, some authors have demonstrated that the most important variable determining hydrocortisone bioavailability is weight; therefore, the authors advocated a weight-related dosing regimen [9]. Furthermore, there is no established cutoff of 17-OHP levels in adults, and probably the optimal dose of glucocorticoids is that which fails to fully suppress 17OHP and maintains androgens in the mid-normal range.

\section{Mineralocorticoid Treatment}

Mineralocorticoid treatment should be continuous in patients with the SW form and is achieved with fludrocortisone. The dose should be adjusted to avoid hypertension and to maintain plasma renin activity in the upper normal range, although there is no consensus on the exact therapeutic goal of this treatment in adult patients. The use of fludrocortisone therapy in patients with the SV form of $\mathrm{CAH}$ should be recommended because it might allow management with lower doses of glucocorticoids $[5,10]$.

\section{Adrenalectomy}

The use of bilateral adrenalectomy in the management of CAH is controversial. Only small series of adult patients have been reported to date, the largest including 5 patients (table 1) [11-14]. Bilateral adrenalectomy was per- 
Table 2. Clinical characteristics of the 45 patients [28]

\begin{tabular}{llcc}
\hline & $\begin{array}{l}\text { SW } \\
(\mathrm{n}=23)\end{array}$ & $\begin{array}{l}\text { SV } \\
(\mathrm{n}=12)\end{array}$ & $\begin{array}{l}\text { NCF } \\
(\mathrm{n}=10)\end{array}$ \\
\hline Sex (F/M) & $16 / 7$ & $11 / 1$ & $9 / 1$ \\
Age, years & $27.5 \pm 1.1$ & $35.5 \pm 2.2^{\mathrm{a}, \mathrm{c}}$ & $25.9 \pm 2.3$ \\
Height, m & $1.59 \pm 0.02$ & $1.54 \pm 0.03$ & $1.63 \pm 0.02^{\mathrm{b}}$ \\
BMI & $25.1 \pm 0.9$ & $26.1 \pm 1.4$ & $24.5 \pm 1.8$ \\
Hydrocortisone, mg/m ${ }^{2}$ & $18.3 \pm 0.9$ & $17.2 \pm 1.1$ & $14.7 \pm 2.2$ \\
Fludrocortisone, mg/day & $81.2 \pm 7.5$ & $81.2 \pm 11.9$ & \\
Duration of treatment, years & $27.1 \pm 1.0$ & $31.7 \pm 2.8$ & $20.3 \pm 2.7^{\mathrm{a}, \mathrm{b}}$ \\
T score & & & \\
$\quad$ Femoral neck (SD) & $-0.86 \pm 0.23$ & $-1.14 \pm 0.28$ & $0.01 \pm 0.52^{\mathrm{b}}$ \\
$\quad$ Lumbar spine (SD) & $-1.09 \pm 0.26$ & $-0.51 \pm 0.45$ & $-0.04 \pm 0.62$ \\
HOMA & $1.58 \pm 0.26$ & $2.01 \pm 0.91$ & $1.39 \pm 0.19$ \\
\hline
\end{tabular}

${ }^{\mathrm{a}} \mathrm{p}<0.05$ versus SW patients; ${ }^{\mathrm{b}} \mathrm{p}<0.05$ versus SV patients; ${ }^{\mathrm{c}} \mathrm{p}<0.05$ versus NCF patients. formed only in CAH women, all with poor hormonal control, in whom there were three main indications, i.e. infertility, virilization and obesity. The outcome of surgery was positive in all reported cases, with respect to weight loss, fall in circulating androgen and fertility. Compliance with therapy pre- and postoperatively is one of the major required conditions before performing this surgery in $\mathrm{CAH}$ patients. Larger series are needed to evaluate more precisely the benefit of this treatment in $\mathrm{CAH}$ patients, especially in men, in whom the postoperative increase in ACTH levels could worsen the adrenal rest tumors.

\section{Bone Mineral Density}

Osteoporosis has been an understandable concern for adults with $\mathrm{CAH}$ who may receive or have received supraphysiological doses of glucocorticoids. Some previous reports on bone mineral density (BMD) in adult $\mathrm{CAH}$ patients showed no significant differences in BMD between patients with $\mathrm{CAH}$ and controls as measured by DXA [15-20], but others have found lower BMD z scores in all or certain subpopulations of CAH patients [21-28]. These reports differ with respect to age selections and glucocorticoid regimens. In reports documenting a BMD reduction, this outcome has been attributed to an accumulated effect of prolonged exposure to excess glucocorticoids during infancy and childhood. The role of each of these factors has been evaluated in a number of studies published over the last decade, often with conflicting results. Most studies are retrospective, include mixed populations (children and young adults), have a small sample size, and are unable to precisely assess the effect of cumulative glucocorticoid doses. Moreover, only 2 studies included patients older than 50 years $[21,23]$. In our population, including 45 adult patients, we found that osteopenic subjects had higher hydrocortisone doses than subjects with normal BMD (table 2) [28]. This was in agreement with recent reports, which had also demonstrated lower BMD in adult CAH patients, attributing the decrease to excessive cortisol replacement $[21,22,26]$. Their participants had significantly lower lumbar and femoral neck BMD scores than controls. Studies conducted in subjects under glucocorticoid treatment have shown that long-term treatment may induce osteoporosis, with biochemical evidence of decreased bone turnover and bone loss occurring principally within the first 6 months of treatment $[21,29]$. It is also possible that 25 hydroxyvitamin D deficiency, observed in $44 \%$ of our patients, plays a role in the decreased BMD. Therefore, vitamin D status should be systematically determined in $\mathrm{CAH}$ patients, and calcium and vitamin D supplementation should be recommended in patients with vitamin $\mathrm{D}$ deficiency and those receiving high dose of steroids. A recent study suggests an association between oversuppression of adrenal androgen and decreased BMD in adult CAH women [26]. Finally, some studies suggest that higher BMI may offer some protection against bone density loss in adult patients with CAH [28]. Biochemical markers of bone turnover have also been evaluated in patients with CAH $[15,19,27]$. Bone turnover was lower in patients with CAH than in controls, and osteocalcin levels correlated positively with growth velocity and negatively with BMD $[15,19]$. Another recent study showed 
higher bone-specific alkaline phosphatase and type I collagen C-terminal telopeptide concentrations in CAH patients compared with control subjects, but this did not correlate with the actual glucocorticoid dose or the mean dose use during the previous 7 years [27]. Despite these conflicting results, and because some studies showed that young adult patients with the classical form of $\mathrm{CAH}$ have decreased bone density values compared with healthy controls and that this may put them at risk for developing osteoporosis early in life, we recommend systematically checking BMD in adult CAH patients. The frequency of such a measure during adulthood remains unresolved, and probably depends on the initial result of the BMD.

\section{Metabolism}

Body mass index (BMI) is found to be elevated in most $[21,23,28,30]$ but not all $[15,22]$ reports on CAH patients. One study has showed an increased risk of obesity among children and adolescents with classic $\mathrm{CAH}$ due to 21-OH deficiency, compared with a reference population [31]. There was a slight but significantly positive correlation of BMI with the current hydrocortisone dosage of the patients. Moreover, fat mass measurements by DXA seem to be elevated in young CAH adults $[18,20,22]$. We also recently reported increased $\mathrm{BMI}$ in our $\mathrm{CAH}$ population, as in other studies and a significantly positive correlation between an insulin resistance index, homeostatic model assessment (HOMA), and BMI, and between HOMA and 17-OHP levels, which persisted after adjusting on BMI (table 2) [28]. Another recent study showed higher insulin levels in the $\mathrm{CAH}$ women above 30 years compared with controls. Moreover, they reported a high frequency of gestational diabetes among these patients, potentially indicating a higher risk of developing diabetes in the near future [32]. Thus, there is a need for long-term follow-up and further studies of insulin sensitivity in $\mathrm{CAH}$. In another study, an increased intima-media thickness has been reported suggesting there is a need for longterm follow-up and further studies of the determination of cardiovascular risk in $\mathrm{CAH}$ [33]. Indeed, some authors have shown that hyperandrogenism could be an independent risk factor for hyperinsulinism in adolescent girls and women $[34,35]$. This is consistent with a study of young women with untreated, non-classical 21-OH deficiency, who were demonstrated to be significantly less sensitive to insulin than control subjects [36]. On the other hand, this insulin resistance may expose these $\mathrm{CAH}$ women to an increased risk of developing polycystic ova-

Long-Term Follow-Up of CAH Patients ries, then enhancing androgen production, and the cardiovascular risk of insulin resistance. Recently, Charmandari et al. [37] reported significantly higher BMI values together with elevated serum leptin and insulin levels and an increased insulin resistance index and reduced catecholamine levels in 18 children with $\mathrm{CAH}$, compared with healthy control subjects. The authors of this study explain this difference by long-term differences in adrenomedullary function, androgen concentrations and exposure to glucocorticoids. Further studies are needed to determine the regulation of insulin and glucose in patients with $\mathrm{CAH}$, who may benefit from prevention and treatment of their potential insulin resistance. Another important cardiovascular risk factor is hypertension. The prevalence of hypertension in adults with $21-\mathrm{OH}$ deficiency has not yet been reported, but in children and adolescents, Roche et al. [38] found that 58\% had increased systolic and $24 \%$ had increased diastolic blood pressure when measuring 24-hour ambulatory blood pressure. Moreover, other data show altered 24-hour blood pressure profiles with elevated systolic levels which correlate with the degree of overweight and obesity [39]. Finally, to date, reports on cardiovascular morbidity and mortality in patients with classic $\mathrm{CAH}$ are lacking.

\section{Fertility and Reproductive Axis in CAH Women}

Reduced fertility has been reported in patients with classic and non-classic CAH, especially in SW women [40-43]. The most important study was done in 1987 and included $80 \mathrm{CAH}$ women [40]. Half of these women did not have sexual activity and among those with sexual activity, the fertility rate was low. Among 25 women with the SV form and adequate vaginal opening, the fertility rate was $60 \%$, meanwhile among the 15 women with the SW form and adequate vaginal opening, the fertility rate was only $7 \%$. However, more recent data suggest that fertility rates have significantly improved from $60 \%$ in SW patients to $80 \%$ in SV patients [41], largely owing to earlier treatment of $\mathrm{CAH}$, improvements in compliance with therapy, and surgical advances in genital reconstruction leading to an increased percentage of patients with sexual activity [41-44].

Several factors have been suggested to contribute to the disturbed reproductive axis in CAH females: adrenal overproduction of androgens and progesterone, ovarian hyperandrogenism, neuroendocrine factors, feminizing surgery, and psychological factors. Indeed, several hormonal factors might play a role: aromatization of excess adrenal 
androstenedione and hypersecretion of progesterone might interfere with LH and FSH secretion [45, 46]. Elevated progesterone or other sex steroid levels could induce abnormal ovarian function by programming the hypothalamus early in development [47] and induce hypersecretion of LH at puberty. Androgen excess might directly damage the ovaries. Deficient 21-hydroxylation of progesterone in the zona glomerulosa of SW patients may lead to a further increase in adrenocortical progesterone secretion, causing elevated levels during the follicular phase. This adrenal progesterone can prevent thickening of the endometrium in the follicular phase. This may also occur in well-substituted or oversubstituted patients, as shown in one study, due to the progestational potency of 17-OHP that has been reported to be $1 \%$ that of progesterone [ 45 , 46]. Menstrual irregularities, from oligomenorrhea to amenorrhea, are frequent in $\mathrm{CAH}$ women and they are estimated to be present in $64-68 \%$ of SW women and $55-$ $75 \%$ of SV women [40, 41]. Hirsutism is present in $20-30 \%$ of the patients. Due to the role of multiple hormonal factors, the regularity of the menstrual cycle can be considered as an important measure of therapeutic control in women with CAH. The relation between obesity, hyperandrogenism, insulin resistance, and the development of polycystic ovaries in $\mathrm{CAH}$ requires further study.

The second factor implicated in the reduced fertility of $\mathrm{CAH}$ women is feminizing surgery. Obviously, there is a relationship between sexual activity and vaginal function [40]. There are few long-term follow-up studies evaluating the outcome of surgery in $\mathrm{CAH}$ women, and most of those studies have small sample sizes. Genital surgery and especially the timing of vaginoplasty has been a matter of debate. The long-term aims of this surgery are to normalize the appearance and functioning of the adult female genitalia. One recent study showed that despite the poor outcome of the initial single-stage surgery in infancy and re-operation in puberty in most of the patients due to vaginal stricture or vaginal stenosis, the adult outcome seems more positive than the findings in the few previous reports, especially with respect to sexual development and activity [48]. Nevertheless, two recent studies have shown impaired sexual function in $\mathrm{CAH}$ women who previously had genital surgery, potentially related to the compromised sensitivity and restricted introitus [49, 50]. Data on the youngest adult generation who may have benefited from improved insights in surgical methods are needed, especially with respect to adult sexual function and the patient's satisfaction with treatment. All these data also underscore the importance of psychological support in the treatment of children with CAH.
Finally, some psychological factors can explain the reduced fertility. Studies of female patients with classic $\mathrm{CAH}$ suggest that exposure to excess androgens during prenatal development influences brain development. Indeed, female patients with classic $\mathrm{CAH}$ have been found to have more male-typical childhood play than unaffected girls, are more likely to use physical aggression in conflict situations, and have less interest in infants and nurturing activities [5]. Nevertheless, recent studies have shown that these women have normal sexual identification, and do not have gender identity confusion [51]. Sexual preference has been studied, but the results are conflicting, with large variability in heterosexuality and homosexuality rates, probably due to the different methods of these studies.

Analogous to testicular adrenal rest tumors, ovarian adrenal rest tumors have been described, but only in case reports [52-54]. It is very likely that ovarian adrenal rest tumors, if present, could impair ovarian function in $\mathrm{CAH}$ females by displacing normal ovarian tissue and by locally producing steroids, which interfere with normal ovarian function. Systematic study of ovarian adrenal rest tumors by pelvic ultrasonography and MRI was not able to detect them in any of the $13 \mathrm{CAH}$ women studied, according to the diagnostic criteria derived from the imaging features of testicular adrenal rest tumors [55]. This suggests that ovarian adrenal rest tumors in $\mathrm{CAH}$ females are rare, in contrast to the high prevalence of testicular adrenal rest tumors in $\mathrm{CAH}$ males.

Successful pregnancy outcomes are possible in women with classic $\mathrm{CAH}$, and careful management during gestation is indicated, especially if the fetus is female [for review see 56]. In pregnant women with $21-\mathrm{OH}$ deficiency, glucocorticoids that are inactivated by placental $11 \beta$-hydroxysteroid dehydrogenase type II (i.e. hydrocortisone, prednisone) are recommended to minimize fetal adrenal suppression. Dexamethasone, which provides longer and more effective suppression of adrenal androgen production, is transferred across the placenta without oxidation of the 11-hydroxyl group and can suppress the fetal adrenal gland $[57,58]$, and this treatment should be reserved for pregnancies in which the fetus is at risk of $\mathrm{CAH}$.

\section{Fertility and Reproductive Axis in CAH Men}

Male patients with CAH may present impaired gonadic function and infertility. However, the majority of longterm follow-up data concern female patients. It appears that adult males with $\mathrm{CAH}$ face a dual problem: adrenal 
steroid overproduction, especially androgen and progesterone, might interfere with FSH and LH production, resulting in gonadotropin deficiency and consequent small testicular size and infertility $[59,60]$, whereas adrenal rests can destroy the testicular tubules and lead to infertility or may interfere directly with the function of normal testicular tissue in a mechanical way or by local steroid production $[59,60]$. Optimal control of adrenal steroid secretion appears then to be crucial to preserve fertility in adult males with CAH. However, there are no sufficient long-term hormonal data to determine the role of treatment of $\mathrm{CAH}$ in the prevention of gonadic abnormalities.

Testicular adrenal rest tumors in $\mathrm{CAH}$ due to $21-\mathrm{OH}$ deficiency have been described for many years but they have been only recently carefully investigated $[59,60]$. It is believed that these testicular tumors in CAH patients originate from aberrant adrenal tissue. Biochemical studies in vitro and in vivo support this hypothesis by showing adrenal-specific $11 \beta$-hydroxysteroids in the testicular tumors [61]. These testicular adrenal rest tumors seem to be ACTH-dependent, since they develop during periods of sustained elevation of ACTH and decrease in size during the administration of glucocorticoids. Nevertheless, some studies report the development of testicular tumors despite good hormonal control, suggesting that undertreatment is not the only cause of prevalence of testicular tumors in these patients $[59,60]$. Such tumors can be misdiagnosed as Leydig cell tumors. However, unlike Leydig cell tumors, they are most often bilateral, occur in men with poor adrenal suppression, and decrease in size with increased glucocorticoid suppression [1]. In case of doubt, a biopsy needs to be considered, but this is uncommon. Conflicting results exist concerning the prevalence of such tumors, ranging from 30 to $95 \%$ of the patients, depending on the selection of patients and methods of detection (clinical examination or ultrasonography) [1, 59-61]. Furthermore, their impact on fertility has not been yet completely established. Testicular function, both semen production and testosterone secretion, may be impaired in these patients, especially when large testicular tumors are present $[59,60]$. Indeed, a study has shown testicular dysfunction, with decreased levels of plasma testosterone, in 6 of the 17 patients studied, whereas poor semen quality was demonstrated in 7 of 11 patients [60]. The preferred method of treatment of testicular adrenal rest tumors in patients with $\mathrm{CAH}$ is intensifying glucocorticoid therapy. This may lead to a decrease in tumor size and improvement in testicular function. If the testicular size is not reduced after suppression therapy or a

Long-Term Follow-Up of CAH Patients
Table 3. Potential long-term consequences of $\mathrm{CAH}$ and suggested follow-up of the patients

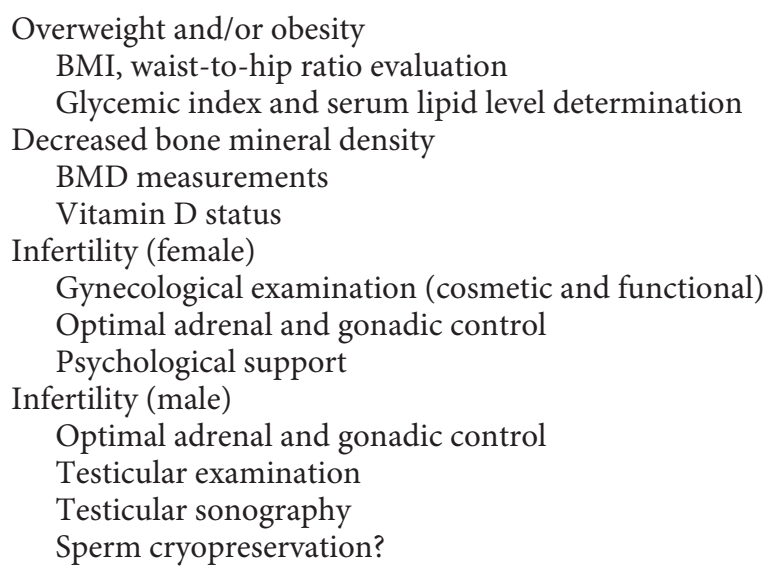

side effect of glucocorticoid dose is noted, surgical intervention is often considered; however, it is usually associated with a worsening of testicular function [62, 63]. A recent study has shown that testis-sparing surgery does not improve pituitary-gonadal hormonal function and semen analysis despite successful removal of the tumors in $8 \mathrm{CAH}$ men [63]. Further studies are needed to evaluate the consequences of such surgery at an earlier stage of the natural history of adrenal rest tumors. We have recently evaluated whether long-term op'DDD treatment was able to improve adrenal rest tumors in 3 adult patients with classical CAH since intensification of the glucocorticoid treatment was inefficient or impossible due to major side effects. We observed improvements in sperm count, testicular adrenal rest tumor size and hormonal gonadal function after 24-36 months of mitotane treatment [64]. Nevertheless, this has to be confirmed in a larger series and has raised several questions, especially with regard to the duration of treatment, the relapse of adrenal rest tumors after mitotane withdrawal, and the impact of mitotane on sperm.

Using regular testicular examination and ultrasonography, the early detection and treatment of testicular adrenal rest tumors should be of primary concern in men with CAH. Ultrasound findings include hypoechogenic lesions with hyperechogenic reflections, most often adjacent to the mediastinum testis [65]. Moreover, semen analysis should be performed in these patients. Finally, it seems prudent for many adult endocrinologists to propose systematic semen cryopreservation.

In conclusion, $\mathrm{CAH}$ patients should be carefully followed up, from childhood to adulthood, by multidisci- 
plinary teams who have knowledge of CAH (table 3). Nevertheless, most studies represent only one window in time. Prospective studies, in a European network, are needed to better understand the adult consequences of $\mathrm{CAH}$, especially the natural history of the disease, the impact of long-term glucocorticoid replacement on bone health, and the impact of overweight, which may be associated with metabolic syndrome, on increased vascular risk. This approach could define the future guidelines of care of children with $\mathrm{CAH}$ in order to prevent its longterm consequences.

\section{Acknowledgement}

Zeina Chaktoura is the recipient of a grant from the Association Surrénales.

\section{References}

$\checkmark 1$ White PC, Speiser PW: Congenital adrenal hyperplasia due to 21-hydroxylase deficiency. Endocr Rev 2000;21:245-291.

$\checkmark 2$ Dupont B, Oberfield SE, Smithwick EM, Lee TD, Levine LS: Close genetic linkage between HLA and congenital adrenal hyperplasia (21-hydroxylase deficiency). Lancet 1977;2:1309-1312.

3 Levine LS, Zachmann M, New MI, Prader A, Pollack MS, O’Neill GJ, Yang SY, Oberfield SE, Dupont B: Genetic mapping of the 21-hydroxylase-deficiency gene within the HLA linkage group. N Engl J Med 1978;299:911915.

4 Morel Y, Tardy V, Costa JM, Forest MG, David M: 21 hydroxylase deficiency: new strategies emerging from molecular studies. Ann Endocrinol (Paris) 2003;64:456-470.

5 Merke DP, Bornstein SR: Congenital adrenal hyperplasia. Lancet 2005;365:2125-2136.

6 Therrell BL: Newborn screening for congenital adrenal hyperplasia. Endocrinol Metab Clin North Am 2001;30:15-30.

$\checkmark 7$ Charmandari E, Johnston A, Brook CG, Hindmarsh PC: Bioavailability of oral hydrocortisone in patients with congenital adrenal hyperplasia due to 21-hydroxylase deficiency. J Endocrinol 2001;169:65-70.

$\checkmark 8$ Charmandari E, Matthews DR, Johnston A, Brook CG, Hindmarsh PC: Serum cortisol and 17-hydroxyprogesterone interrelation in classic 21-hydroxylase deficiency: is current replacement therapy satisfactory? J Clin Endocrinol Metab 2001;86:4679-4685.

$\checkmark 9$ Ross RJ, Rostami-Hodjegan A: Timing and type of glucocorticoid replacement in adult congenital adrenal hyperplasia. Horm Res 2005;64(suppl 2):67-70.

-10 Cutler GB Jr, Laue L: Congenital adrenal hyperplasia due to 21-hydroxylase deficiency. N Engl J Med 1990;323:1806-1813.

-11 Warinner SA, Zimmerman D, Thompson GB, Grant CS: Study of three patients with congenital adrenal hyperplasia treated by bilateral adrenalectomy. World J Surg 2000;24: 1347-1352.

-12 Bruining H, Bootsma AH, Koper JW, Bonjer J, de Jong FF, Lamberts SW: Fertility and body composition after laparoscopic bilateral adrenalectomy in a 30-year-old female with congenital adrenal hyperplasia. J Clin Endocrinol Metab 2001;86:482-484.

13 Gmyrek GA, New MI, Sosa RE, Poppas DP: Bilateral laparoscopic adrenalectomy as a treatment for classic congenital adrenal hyperplasia attributable to 21-hydroxylase deficiency. Pediatrics 2002;109:e28.

14 Ogilvie CM, Rumsby G, Kurzawinski T, Conway GS: Outcome of bilateral adrenalectomy in congenital adrenal hyperplasia: one unit's experience. Eur J Endocrinol 2006; 154:405-408.

15 Guo CY, Weetman AP, Eastell R: Bone turnover and bone mineral density in patients with congenital adrenal hyperplasia. Clin Endocrinol (Oxf) 1996;45:535-541.

16 Gussinye M, Carrascosa A, Potau N, Enrubia M, Vicens-Calvet E, Ibanez L, Yeste D: Bone mineral density in prepubertal and in adolescent and young adult patients with the salt-wasting form of congenital adrenal hyperplasia. Pediatrics 1997;100:671-674.

17 Mora S, Saggion F, Russo G, Weber G, Bellini A, Prinster C, Chiumello G: Bone density in young patients with congenital adrenal hyperplasia. Bone 1996;18:337-340.

18 Stikkelbroeck NM, Oyen WJ, van der Wilt GJ, Hermus AR, Otten BJ: Normal bone mineral density and lean body mass but increased fat mass in young adult patients with congenital adrenal hyperplasia. J Clin Endocrinol Metab 2003;88:1036-1042.

19 Girgis R, Winter JS: The effects of glucocorticoid replacement therapy on growth, bone mineral density, and bone turnover markers in children with congenital adrenal hyperplasia. J Clin Endocrinol Metab 1997;82: 3926-3929.

20 Christiansen P, Molgaard C, Muller J: Normal bone mineral content in young adults with congenital adrenal hyperplasia due to 21-hydroxylase deficiency. Horm Res 2004; 61:133-136.

21 Jaaskelainen J, Voutilainen R: Bone mineral density in relation to glucocorticoid substitution therapy in adult patients with 21-hydroxylase deficiency. Clin Endocrinol (Oxf) 1996;45:707-713.

22 Hagenfeldt K, Ritzen EM, Ringertz H, Helleday J, Carlstrom K: Bone mass and body composition of adult women with congenital virilizing 21-hydroxylase deficiency after glucocorticoid treatment since infancy. Eur J Endocrinol 2000;143:667-671.

23 Cameron FJ, Kaymakci B, Byrt EA, Ebeling PR, Warne GL, Wark JD: Bone mineral density and body composition in congenital adrenal hyperplasia. J Clin Endocrinol Metab 1995;80:2238-2243.

24 Paganini C, Radetti G, Livieri C, Braga V, Migliavacca D, Adami S: Height, bone mineral density and bone markers in congenital adrenal hyperplasia. Horm Res 2000;54: 164-168.

25 de Almeida Freire PO, de Lemos-Marini SH, Maciel-Guerra AT, Morcillo AM, Matias Baptista MT, de Mello MP, Guerra G Jr: Classical congenital adrenal hyperplasia due to 21-hydroxylase deficiency: a cross-sectional study of factors involved in bone mineral density. J Bone Miner Metab 2003;21:396401.

26 King JA, Wisniewski AB, Bankowski BJ, Carson KA, Zacur HA, Migeon CJ: Long term corticosteroid replacement and bone mineral density in adult women with classical congenital adrenal hyperplasia. J Clin Endocrinol Metab 2006;9:865-869.

27 Sciannamblo M, Russo G, Cuccato D, Chiumello G, Mora S: Reduced bone mineral density and increased bone metabolism rate in young adult patients with 21-hydroxylase deficiency. J Clin Endocrinol Metab 2006;91: 4453-4458.

28 Bachelot A, P-Bureau G, Thibaud E, Laborde K, Pinto G, Samara D, Nihoul-Fékété C, Kuttenn F, Polak M, Touraine P: Long-term outcome of patients with congenital adrenal hyperplasia due to 21-hydroxylase deficiency. Horm Res 2006;67:268-276.

29 Gallagher MP, Levine LS, Oberfield SE: A review of the effects of therapy on growth and bone mineralization in children with congenital adrenal hyperplasia. Growth Horm IGF Res 2005;15(suppl A):S26-S30.

30 Cornean RE, Hindmarsh PC, Brook CGD: Obesity in 21-hydroxylase deficient patients. Arch Dis Child 1998;78:261-263.

31 Volkl TM, Simm D, Beier C, Dorr HG: Obesity among children and adolescents with 
classic congenital adrenal hyperplasia due to 21-hydroxylase deficiency. Pediatrics 2006; 117:e98-e105.

- 32 Falhammar H, Filipsson H, Holmdahl G, Janson PO, Nordenskjold A, Hagenfeldt K, Thoren M: Metabolic profile and body composition in adult women with congenital adrenal hyperplasia due to 21-hydroxylase deficiency. J Clin Endocrinol Metab 2007;92: $110-116$.

- 33 Sartorato P, Zulian E, Benedini S, Mariniello B, Schiavi F, Bilora F, Pozzan G, Greggio N, Pagnan A, Mantero F, Scaroni C: Cardiovascular risk factors and ultrasound evaluation of intima-media thickness at common carotids, carotid bulbs, and femoral and abdominal aorta arteries in patients with classic congenital adrenal hyperplasia due to 21hydroxylase deficiency. J Clin Endocrinol Metab 2007;92:1015-1018.

34 Huppert J, Chiodi M, Hillard PJ: Clinical and metabolic findings in adolescent females with hyperandrogenism. J Pediatr Adolesc Gynecol 2004;17:103-108.

- 35 Golden SH, Ding J, Szklo M, Schmidt MI, Duncan BB, Dobs A: Glucose and insulin components of the metabolic syndrome are associated with hyperandrogenism in postmenopausal women: the atherosclerosis risk in communities study. Am J Epidemiol 2004; 160:540-548.

-36 Speiser PW, Serrat J, New MI, Gertner JM: Insulin insensitivity in adrenal hyperplasia due to nonclassical steroid 21-hydroxylase deficiency. J Clin Endocrinol Metab 1992;75: 1421-1424.

37 Charmandari E, Weise M, Bornstein SR, Eisenhofer GR, Keil MF, Chrousos GP, Merke DP: Children with classic congenital adrenal hyperplasia have elevated serum leptin concentrations and insulin resistance: potential clinical implications J Clin Endocrinol Metab 2002;87:2114-2120.

- 38 Roche EF, Charmandari E, Dattani MT, Hindmarsh PC: Blood pressure in children and adolescents with congenital adrenal hyperplasia (21-hydroxylase deficiency): a preliminary report. Clin Endocrinol (Oxf) 2003;58:589-596.

- 39 Volkl TM, Simm D, Dotsch J, Rascher W, Dorr HG: Altered 24-hour blood pressure profiles in children and adolescents with classical congenital adrenal hyperplasia due to 21-hydroxylase deficiency. J Clin Endocrinol Metab 2006;91:4888-4895.

40 Mulaikal RM, Migeon CJ, Rock JA: Fertility rates in female patients with congenital adrenal hyperplasia due to 21-hydroxylase deficiency. N Engl J Med 1987;316:178-182.

-41 Premawardhana LD, Hughes IA, Read GF, Scanlon MF: Longer tem outcome in females with congenital adrenal hyperplasia (CAH): the Cardiff experience. Clin Endocrinol (Oxf) 1997;46:327-332

42 Krone N, Wachter I, Stefanidou M, Roscher AA, Schwarz HP: Mothers with congenital adrenal hyperplasia and their children: outcome of pregnancy, birth and childhood. Clin Endocrinol (Oxf) 2001;55:523-529.

43 Lo JC, Grumbach MM: Pregnancy outcomes in women with congenital virilizing adrenal hyperplasia. Endocrinol Metab Clin North Am 2001;30:207-229.

44 Azziz R, Mulaikal RM, Migeon CJ, Jones HW Jr, Rock JA: Congenital adrenal hyperplasia: long-term results following vaginal reconstruction. Fertil Steril 1986;46:1011-1014.

45 Helleday J, Siwers B, Ritzen EM, Carlstrom K: Subnormal androgen and elevated progesterone levels in women treated for congenital virilizing 21-hydroxylase deficiency. J Clin Endocrinol Metab 1993;76:933-936.

46 Holmes-Walker DJ, Conway GS, Honour JW, Rumsby G, Jacobs HS: Menstrual disturbance and hypersecretion of progesterone in women with congenital adrenal hyperplasia due to 21-hydroxylase deficiency. Clin Endocrinol (Oxf) 1995;43:291-296.

47 Barnes RB, Rosenfield RL, Ehrmann DA, Cara JF, Cuttler L, Levitsky LL, Rosenthal IM: Ovarian hyperandrogynism as a result of congenital adrenal virilizing disorders: evidence for perinatal masculinization of neuroendocrine function in women. J Clin Endocrinol Metab 1994;79:1328-1333.

48 Stikkelbroeck NM, Beerendonk C, Willemsen W, Schreuders-Bais CA, Feitz W, Rieu P, Hermus A, Otten BJ: The long term outcome of feminizing genital surgery for congenital adrenal hyperplasia: anatomical, functional and cosmetic outcomes, psychosexual development, and satisfaction in adult female patients. J Pediatr Adolesc Gynecol 2003;16: 289-296.

49 Alizai NK, Thomas DF, Lilford RJ, Batchelor AG, Johnson N: Feminizing genitoplasty for congenital adrenal hyperplasia: what happens at puberty? J Urol 1999;161:1588-1591.

-50 Creighton SM, Minto CL, Steele SJ: Objective cosmetic and anatomical outcomes at adolescence of feminising surgery for ambiguous genitalia done in childhood. Lancet 2001;358:124-125.

51 Ogilvie CM, Crouch NS, Rumsby G, Creighton SM, Liao LM, Conway GS: Congenital adrenal hyperplasia in adults: a review of medical, surgical and psychological issues. Clin Endocrinol (Oxf) 2006;64:2-11.

52 Claahsen-van der Grinten HL, Hulsbergenvan de Kaa CA, Otten BJ: Ovarian adrenal rest tissue in congenital adrenal hyperplasia - a patient report. J Pediatr Endocrinol Metab 2006;19:177-182.

53 Russo G, Paesano P, Taccagni G, Del Maschio A, Chiumello G: Ovarian adrenal-like tissue in congenital adrenal hyperplasia. $\mathrm{N}$ Engl J Med 1998;339:853-854.

54 Al Ahmadie HA, Stanek J, Liu J, Mangu PN, Niemann T, Young RH: Ovarian 'tumor' of the adrenogenital syndrome - the first reported case. Am J Surg Pathol 2001;25:14431450.
55 Stikkelbroeck NM, Hermus A, Schouten D, Suliman H, Jager G, Braat D, Otten BJ: Prevalence of ovarian adrenal rest tumours and polycystic ovaries in females with congenital adrenal hyperplasia: results of ultrasonography and MR imaging. Eur Radiol 2004;14: 1802-1806.

56 Hughes IA: Congenital adrenal hyperplasia: 21-hydroxylase deficiency in the newborn and during infancy. Semin Reprod Med 2002:20:229-242.

57 Forest MG, Tardy V, Nicolino M, David M, Morel Y: 21-Hydroxylase deficiency: an exemplary model of the contribution of molecular biology in the understanding and management of the disease. Ann Endocrinol (Paris) 2005;66:225-232.

- 58 New MI, Carlson A, Obeid J, Marshall I, Cabrera MS, Goseco A, Lin-Su K, Putnam AS, Wei JQ, Wilson RC: Prenatal diagnosis for congenital adrenal hyperplasia in 532 pregnancies. J Clin Endocrinol Metab 2001;86: 5651-5657.

59 Cabrera MS, Vogiatzi MG, New MI: Long term outcome in adult males with classic congenital adrenal hyperplasia. J Clin Endocrinol Metab 2001;86:3070-3078.

60 Stikkelbroeck N, Otten BJ, Pasic A, Jager GJ, Sweep C, Noordam K, Hermus AR: High prevalence of testicular adrenal rest tumors, impaired spermatogenesis, and Leydig cell failure in adolescent and adult males with congenital adrenal hyperplasia. J Clin Endocrinol Metab 2001;86:5721-5728.

61 Blumberg-Tick J, Boudou P, Nahoul K, Schaison G: Testicular tumors in congenital adrenal hyperplasia: steroid measurements from adrenal and spermatic veins. J Clin Endocrinol Metab 1991;73:1129-1133.

62 Walker BR, Skoog SJ, Winslow BH, Canning DA, Tank ES: Testis sparing surgery for steroid unresponsive testicular tumors of the adrenogenital syndrome. J Urol 1997;157: 1460-1463.

63 Claahsen-van der Grinten HL, Otten BJ, Takahashi S, Meuleman EJ, Hulsbergen-van de Kaa C, Sweep FC, Hermus AR: Testicular adrenal rest tumours in adult males with congenital adrenal hyperplasia: evaluation of pituitary-gonadal function before and after successful testis-sparing surgery in $8 \mathrm{pa}$ tients. J Clin Endocrinol Metab 2007;92:612.

64 Bachelot A, Chanson P, Rocher L, Salenave S, Laborde K, Kuttenn F, Morel Y, Touraine P, Young J: Effects of mitotane on testicular adrenal rest tumors size, sperm count and adrenal steroidogenesis in patients with congenital adrenal hyperplasia (CAH) due to 21-hydroxylase deficiency. ESPE/LWPES 7th Joint Meeting in Paedriatric Endocrinology. Horm Res 2005;64(suppl 1):42.

65 Stikkelbroeck NM, Suliman HM, Otten BJ, Hermus AR, Blickman JG, Jager GJ: Testicular adrenal rest tumours in postpubertal males with congenital adrenal hyperplasia: sonographic and MR features. Eur Radiol 2003;13:1597-1603. 